\title{
Looks and images: video and photo therapy
}

\author{
Oliviero Rossi ${ }^{1}$
}

Recibido: $18 / 07 / 14$

Aceptado: 26/10/14

\begin{abstract}
The art therapytechniques are increasinglyrenewed by the use of new instrumentsas new media (video and photo).Working with imagesis a powerful way to increase the client'sawareness in psychotherapy, because the perceptiveactcouldbringthe therapist to construct with the client the story of his life. The familypictures or personal snapshots are precious and important to stimulate the creative process, the use of metaphors and the contact with emotions. In thisregard, wewillexamine the concepts of personal growth, helping relationship and thesis of existence in the frame of the Gestaltpsychotherapy model. The work isexplaineddeeply, after a theoricalintroduction, takinginspiration from asession of psychotherapy in which the patientworkswith personal photographs.
\end{abstract}

Key words: Psychotherapy, Gestalt, Phototherapy, Art Therapy, Metaphor

\section{Referencia normalizada}

ROSSI O. (2014). "Looks and images: video and photo therapy". En Arteterapia: Papeles de arteterapia y educación artística para la inclusión social Vol.: 9. Páginas 191-202. Madrid.

Looking at a photograph implies to perform a perceptive act aimed at a representation which however, as a photo/film, is a sign of something "there" in a real time and space. In the observation of a photo, we find two levels of perception: in the first level, we look at the environmental field identifying the elements that compose it as belonging to it; in the case of a photo included in a specific perceptual field (eg. the picture is on the table) we'll see it, on one level, as an element of the field in its physical features as a sheet of colored paper, or black and white; but once that the sheet of paper is identified through a perceptual act as a photograph, than we'll relate to it in a different way since, at this time, the act will be facing an element identified as a representation of "something", occurred "somewhere".

In its denotative meaning, this image/representation doesn't explain but shows the observer the place and time in which it was produced; in a sense, the percep-

\footnotetext{
${ }^{1}$ Psychologist and Psychotherapist. Director of the MA "Methodology of photography and video in the aid relationship".
} 
tion becomes an "almost perception" as the physiological features of the act undoubtedly remain, but a transposition of the perceived occurs (for example, a picture of a sunset in black and white, which is objectively a gray scale imprinted on photographic paper, is not interpreted in itself but perceived as if it really was what it represents). The person that is looking at the photograph, at some level, knows that what is observed is just a footprint of something happened elsewhere; at another level, the function of cross reference is almost forgotten and, if the picture is significant in itself, it evokes perceptual and emotional activations as if the person really found him or herself there.

Talking about working with images (video and photo) in psychotherapy means, therefore, to insert an "almost perceptual" dimension as well as the dimension of the "as if", that predisposes to the comparison with the personal existence and the way to lead it.

The photo/video image is part of the perceptive field with the same evidence of every other perceptible object, but it also brings about, at the same time, something less (we don't start actions that a real event would activate) or something more to the act of seeing.

If the person knows that what he's looking at is a photograph or a video, he'll tend to treat the image as an index of something that exists or existed. Insofar as the image is also a narrative and expressively effective representation, it could become important for the person, and activate an intense and particular experience. In the therapeutic relationship, the restructuring work of the emotional/cognitive map of the client is based on this type of experience.

The person, looking at the picture, will access to a range of answers recalled from what he's looking at and from the experience that is constructed and/or reconstructed during this act (e.g. if I observe a picture of a whole of people that I recognize as my family or identify as a family, the experience connected to what I'm observing will give form to my perceptual act). The therapeutic work consists in interacting with this construction or constructing together with the client the story of life that emerges in the relationship. A reference to Gibson's work is now relevant. I will use the synthesis of C. Pennacini (Pennacini C., 2005) to frame the concept: "For Gibson, the visual system and in general the sensory perception is intelligible only in relation with the environment, or rather in a given environment. When Gibson talks about the environment, or sometimes habitat, he would refer to a concept that is relational and not absolute. The environment doesn't exist in itself, it's not a physical world provided with separate features. Gibson says that the environment is a non-dualistic concept that is defined in the relationship between the observer and the reality observed, and together they form a complex system (referring to the theory of systems, Gibson, 1986, p.35) in which "an animal and the environment form an inseparable couple" (p.42), produced exactly from the perceptual processes. Starting from the evolution theory, Gibson considers perception as a main process of the adjustment to the environment. It's a complex system (...) that integrates the five organs of sense, through partial but very important overlapping: "they say that 
the vision depends on the eye, that is connected to the brain. Instead, I'll put forward the hypothesis that the natural vision depends on the eyes put in a head that is on a body that is standing on the ground, and that the brain is just the central organ of an integrated visual system" (p.33) (...). Through this system, the environment with its visible form (Gibson refers to it using the term "layout") deeply interacts with its inhabitant. In evolutionary terms, it implies a change of the organs and the system connected to them, in a particular adjustment form, while in individual and cultural terms the process gives rise to different forms of perceptual (and cognitive) adjustment" (Pennacini C., 2005, p.24).

The utilization I propose regards, therefore, the "almost perceptual field" offered by the photo and video images, that permits the comparison with narrative elements recalled from the perceptual acts of the client. These acts express dynamisms that emerges from the "as if" established in the therapeutic relationship and that promotes the process of awareness and insight of a person. The work with photo/video images enters, for some reasons, in the narrative aspect of the therapeutic relationship as the perceptual acts allow us to construct, in the relation with the environment, the world where our existence happens. The perception, in this sense, could be considered as a relation characterized by its adaptive functions with the perceived object. These operations take shape as emotional/cognitive adjustments, synthetized in a narrative experience.

The big resource of using images probably lies on the fact that, used as mediators in the helping relationship, they activate all the adaptive functions involved in the perceptual act; the reference to the emotional/cognitive adjustments that started the script of life and to the system of beliefs that give shape to the way of living one's life, become obvious.

It is important to consider the images as existential recalls and when these media are introduced in the helping relationship, the technique is modulated in function of the resources that enrich the interaction. The possibility to see oneself again and differently is metaphorically amplified just from the initial perceptual act: the look. From this point of view, the "looking" is to reposition oneself in the environment. As in the real perceptual field, the look is accompanied by postural, proxemics, cognitive and emotional adjustments, that lead to the adjustment to the environmental situation, in the "as if" operation towards the existence proposed in the therapeutic setting, and with the suitable performances or replies we can work with emotional and cognitive actions, this time "as if", more adequate to the current life situations of the client. The "thesis of existence" (the cognitive act through which we give for granted that the image could refer to something that exists or existed) is natural for those who observe this kind of images, because it's peculiar of the process that forms the photographic image: we can think about the difference, for example, between the pictorial representation of a face and the photography of the same face; observing the painting doesn't imply for the observer that the face in the painting should be necessarily existent because it could be entirely produced by the fantasy of a painter; observing a photograph implies, instead, the consideration that the face in some way existed or exists, 
otherwise it would be impossible to shoot it (the same photographic trick works just on the basis of this association between photographic image and existence of the subject in the picture).

The photograph needs the light, either reflected or produced by the shot subject, while for the painting the fantasy of the painter is enough. Knowing that what I'm looking at is a photo/video image necessarily brings the observer to an "elsewhere" and to the context where the image has been captured or recorded and what is reproduced is so culturally acquired as the final product of a technological process that starts from a visible subject to end in an image on a reproducing support.

The "thesis of existence", therefore, has interesting implications on the psychotherapeutic work; by making the client observe photographic or video material, every detail refers to something that the client necessarily supposes it has existed, at least during the shoot.

Obviously, the sense given to these details is all to be discussed but anyway that detail is there, in its past or quite present existence. It's a footprint, a sign, a trace more or less articulated of a passage of existence; that image becomes the index and icon of a moment, a fragment of movement or the proof to have been in the world.

Another interesting point is that an image or a video sequence are interpreted also on the basis of the quantity of "transversal knowledge" they activate in the observer; in other words, these images make direct contact with the cognitive and emotional system that organizes the narrative/recalled meaning. The photo/video image is perceived and contextualized both on the basis of what I know about the situation it refers to (e.g. a picture memory of family events) or something that I reconstruct on the basis of the context in which it is proposed to me (e.g. a news picture accompanied by captions). We can define "transversal knowledge" the cognitive frame that contains and gives sense to what I'm looking at. In the psychotherapy field is important to relate with this "transversal knowledge" because if we highlight the way and the construction through which the client gives sense to the event/image, we could start to promote a process of emotional and cognitive de- construction of the system of beliefs that organizes his script of life in this kind of work. Obviously, this is a fertile ground on which the psychotherapist could promote new knowledge and reconstructions of emotional and cognitive levels that facilitates in the client the improvement of his existential qualities.

In conclusion, interacting with the relations between the client and the (photo/video) images through the illustrated concepts ("almost perceptive field", "thesis of existence" and "transversal knowledge") means, in my point of view, to include in the therapeutic work on the "here and now" the possibility of intervention, respecting the complexity of the client's point of view, when he organizes his relation with the inner and outside environment. If one of the therapeutic problems is offering several points of view to the client on his way to be in the world, the use of mediators that concentrate on the perceptive expressions in the 
helping relationship allow the modification of the narrative he uses to communicate to himself and to others his way to exist.

An example of working with images

(The work began with Paola sitting in front of the photographs she brought and with the psychotherapist that is recording with a camcorder)

Psychotherapist: So, what's this story about the little wizard?...Paolo?

Client: Paola?

T.: So, what's this story?

(The therapist proposes the transformation of the pictures disposed on the ground in a kind of storyboard of a narrative of the client)

C.: That this little sorceress, Paola...but I prefer the little wizard...he wanted to do the magic but he couldn't do it.

T.: Sure, if she wanted to do it like a man!

(Giving value to every detail of the story of a person, it's important to begin underling, on the one hand, how the story of a life is connected to the verbal and narrative details and, on the other hand, how then these details will be left to confront them with the parts of the photographs. This with the purpose of paving the way for the passing from a "transversal knowledge" saturated in regard to that pictures, to an opening to new knowledge that leans on details and the cognitive discrepancies between the story that comes from the pictures and what is visible in the picture)

C.: And she always had this inverted love...

T.: What do you mean?

C.: She was upset by these love affairs. She upset herself in order to be beautiful.

T.: And what did she see?

C.: What did she see? Well, she didn't see anything beautiful around her.

T.: Sure, it depends on where she looked. Where did she look?

(The therapist does an operation aimed at increasing responsibility. In order to come out from a story or a life script that the client tends to consider as a destiny that excludes his/her responsibility in the conduction of his/herlife, it's good to start considering that script as a set of repetitions. These repetitions are transformed in a destiny only if we don't renounce to consider them like that, because I can stop to repeat what is repeated but I can't stop a destiny)

C.: She looked at the people around her, the people she met, especially those on which she was fixed... and she devoted herself to this love, also inverting herself for this love. 
T.: And did these people look at her?

C.: Yes, for a while... And then they didn't look at her anymore

T.: Why?

C.: I don't know...they were fed up.

T.: Why?

C.: Because she wasn't exactly as she showed herself.

T.: I see... and why?

C.: Because she changed herself to have a relationship with them. The relationship changed, she had changed, and she couldn't stand it anymore.

T.: Eh, big deal! you start being a wizard and then suddenly you remember you are a woman and... ah!

(The initial pun is now taken again in order to facilitate the passing from the fanciful narration to the work on the client's reality).

C.: Of course, after a while she wasn't able to be again what she had tried to be before she met these people

T.: Ok, and now that we have discovered what happened against your will, what do you feel?

C.: What I feel?

T.: What do you feel?

C.: It seems just... (snapping the fingers)... well, it's true!

T.: And what shall we do with this?

C.: Eh, we learn one thing...if we don't show ourselves as we are, we don't gain what we want because we can't be in contact with people.

T.: No, and even if you win, at the same time, you lose, because someone else has won...Listen, what do you notice in these pictures? (focusing her attention on the pictures she brought and set in front of her).

(The initial contact and acceptance of a fanciful narration of the self is used as a main part from which we go back to an operation of perception "here and now" on the photographs. In this moment, the initial sense of the pictures begins to be different).

C.: There's nobody of my family... and these are all photographs of a period of my life...chronologically they are photos that represent a moment of big change (she shows the pictures), and then there's the period after, and now... and there isn't my childhood, there isn't my family, which were there in my childhood and still is here nowadays... my boyfriend isn't here physically but I bring him with me in this picture because he shot it and in this situation I was with him(she is pointing a picture where she is looking behind a door).

T.: where?

$\mathrm{C}$ : in the mountains.

T.: and where is he?

C.: He's behind the camera

T.: And you? 
C.: I'm behind the door...I'm looking from behind this door, he is looking from the camera...but I know that later he also came in...but, he's not there...eh...I thought the only important person of my life was my teacher (looking at the photograph becomes an act: that active body's responses in the "here and now organizes the "almost perception" of what's inside the photo)

T.: Look at the pictures you shot... where do you let you teacher walk? (the pictures were set by Paola in a way that the one with her teacher hasn't other pictures below)

C.: I let him walk...here

T.: And what's here?

C.: well...it's me there (Paola has set one photograph of her on the left)

T.: yes but where's he walking?

C.: in the middle

T.: and what is there, in the middle?

C.: There's nothing

(the initial pun, understanding literally what is said, prepares the game the therapist is playing now: in a fussy way, the same random placement of the photographs is no longer considered as such. Each element, both inside the pictures and their placement related to the client, becomes a kind of graphical representation of the client's way of conducting his or her existence. The "thesis of existence" spreads from the photo's contents to the placement as each detail becomes the trace of the client's story).

T.: Exactly, it's where you let your teacher walk. On the void...and I don't know how your teacher feels walking on the void, but I know how human beings feel walking on the void (he uses the teacher to talk about something that later, in the next passage, will be relating to her)

$\mathrm{C} .: \mathrm{He}$ is a human being as well.

T.: Well, I don't know...if he's a human being how does he feel about walking on the void?

C.: ...I feel a lot of pain in this moment (being able to reveal gives access to the emotion. The perceived begins to sound emotionally)

T.: Why? What have you realized?

C.: Because I've realized that I think I have hurt him

T.: No, this is what you have been doing all your life...avoiding feeling guilty by blaming yourself...the problem is that you, in order to advance your teacher, made the void on a part of your life...all that is missing here is what your teacher is walking on...Are you aware of it? And maybe the void is a destination...sometimes it is simply an avoidance... and here, what impresses me in these pictures is the void that you talked about at the beginning: your family, which is missing...by chance your teacher is walking on a part that you left empty...What do you feel? 
(the psychotherapist brings Paola back to her responsibilities and works on false certainties and on the "transversal knowledge" that before gave sense to the photographs)

C.: the point of pain is gradually calming down.

T.: And what do you begin to feel, what is it? What do you see? What is there?

(The therapist turns the display of the camera towards Paola)

C.: There is Paola

T.: Tell her...Paola, I got you out of the teacher's way, I took you away to let the teacher walk...I take you away to let the teacher walk every time that...

C.: I got you out of the teacher's way every time that...every time that...every time that...you would escape

T.: How many intentions... what else are you taking away in this moment? What are you taking away from Paola?

C.: What I am taking away from her...I am taking away... (she starts to look at her making a face to the screen)

T.: By becoming one thousand faces I avoid showing you...

C.: I avoid showing...that I don't like a few things

T.: for example?

C.: I don't like too much intimacy...I don't know...mawkishness

T.: and by apologising about these things I can...

C.: I can express something else...I feel more open and free

T.: Ok, stay in this position and leave your hand (she had the hand put on her chin)... What do you feel?

C.: I have a pain in my neck

T.: So, if you put the void, the risk is...

C.: There's the risk to tire oneself and to fall down

T.: Yes... what are you reproducing, just like your teacher?...letting him walk on the void instead of what is there

C.: It's the same as with the others...I am not showing myself through the things that are there and that I have...

T.: With all the things that allow me to bear everything that is in my head...It could happened that the others start feeling that they can see you but not look at you...put your hand back where it was (under her chin)... what do you feel?

C.: I feel more comfortable

T.: Yes, start talking to those who are not in your photographs

C.: I love you but...

T.: Who are you talking to?

C.: To my sister...her name's Pina...I love her but when I see her I feel sad

T.: and for this reason I cancelled you...

C.: Eh...for this reason I cancelled you

T.: And then, who else do you want to talk to?

C.: I can talk to my father... 
T.: Daddy...

C.: Daddy, before we travelled a lot together, while now I travel alone...

T.: And for this reason I cancelled you

T.: who else?

C.: my mother...

T.: Go...no, put back your hand where it was and let the water go down where it goes (Paola now is crying)

C.: mum, I always want you to go away so, you are the easiest to cancel

T.: And I cancelled you

C.: And I cancelled you

T.: And now I am in all my tears when...let your tears go down, exactly there (on the photograph) and talk to that girl that is in the water (he refers to a photo brought by Paola where she's swimming in the sea)

C.: breathe breathe

T.: sure...tell her... I'm not an empty bottle

C.: I'm not an empty bottle

T.: From my eyes...

C.: From my eyes, water is coming down...there's plenty of water

T.: and I am not an empty bottle

C.: I am not an empty bottle

T.: say it also to your teacher

C.: I am not an empty bottle (raising her voice), it's not necessary to fill me by force

T.: Oh! I'm already full

C.: I'm already full

T.: What I need is not filling me but...

C.: What I need is not filling me, but learning to pour water without breaking the bottle

T.: just like coming out of your shell? Or out from a door? (The camcorder focuses on the picture where Paola appears at the door)

C.: (smiling)... when I am touched I pour water, also from the nose

T.: Sure...look at your expression when you are touched (he frames the picture where she's in the sea). What do you want to say now to that girl that is looking at the water, to that girl, as you said, that doesn't know what to do...if only she knew what to do...look who's coming out from the water...look here (he still refers to the picture where Paola is in the sea)

C.: it's me that is coming out of the water

T.: And now look here (in the screen of the camcorder) ... what is coming out of the water?

C.: Paola...from the water of the eyes

T.: We call them tears...tell her...Paola, you're not empty

C.: Paola, you're not empty

T.: The proof is that something is coming out of the bottle, so it's not empty...where are that tears from? From the eyes and... 
C.: form the eyes and the stomach

T.: tell her what you have in your stomach... in my stomach I have...

C.: in my stomach I have a lot of dices...lots of cans

T.: How many things you have in your stomach that you keep inside as if they weren't there...but they are there, your stomach is full

C.: my stomach is full

T.: If tears come out it means that something is full and not empty

C.: Yes it's full, my stomach is full

T.: eh

C.: eh

T.: I said "eh"

C.: Eh...I am a copycat

T.: Tell the teacher... look teacher, I am a copycat

C.: Look teacher, I am a copycat

T.: If I see you walk on the void there's the risk that I...

C.: There's the risk that I also walk on the void...but he doesn't walk on the void

T.: Yes, but you put him there... he copies himself or you copy yourself, let's see who's to be copied...You know teacher, maybe I'd be better

C.: not walk on the void

T.: that's it...me at least ...

C.: Yes

T.: Tell Paola, too (the attention is directed again to her image on the screen)

C.: Paola don't walk on the void

T.: so remember to...

C.: remember that people are important

T.: ah, are you a person?

C.: I am a person

T.: are you a person?

C.: Paola is a person, Paola you are a person

T.: Empty?

C.: You're not empty, you are full

T.: so what's inside you is important

C.: You are important

T.: And it's not said that you need to leave out what is important to you just to let you teacher walk

C.: Yes

T.: So, what are you feeling?

C.: Relief

T.: As if I realized that...

C.: as if I realized that I'm not completely full

T.: Oh, so you are not completely full? This is a healthy void. Ok, just a word to say hello to Paola, what you want to give to her

C.: (laughing) be quiet Paola 
T.: If you gave a tear to her it could be precious because...

C.: Because it makes plants grow.

Although I kept the original form, the text was modified to make unrecognizable the person involved. For the same reason, though I am sure they would have added more value, I preferred to avoid the photographs. For this, I appeal to the reader's imagination.

\section{References}

BERMAN, Beyond the smile - The therapeutic use of the photograph, Routledge London, 1993.

CAVALLO, M., Identità narrativa, Artiterapie, vol. 5/6, pag. 5-6, 2001.

DE FRANCO, L., CORTESE, M., Ciak, si vive. Grande schermo e piccoli gruppi, Magi Edizioni, Roma, 2004.

GIBSON J. J. Un approccio ecologico alla percezione visiva. Il Mulino, Bologna, 1999

MANGHI, D., Vedere se stessi, Franco Angeli, Milano, 2003.

PENNACINI C. Filmare le culture, Carocci, Roma, 2005

ROSSI, O., Incontrare se stessi: la videoterapia nella relazione d'aiuto. Attualità in Psicologia, anno XX, n³-4, Luglio/Dicembre, EUR, Roma, 2005

ROSSI, O., Le visioni della memoria. Formazione In Psicoterapia Counselling Fenomenologia, vol. 3, pag. 12-23, Roma, 2004.

SCHAEFFER J.M,L'image précarie. Du dispositif photographique, Paris Editions du Seuil, 1987

WHITE, M., La terapia come narrazione, Astrolabio, Roma, 1992. 
${ }^{1}$ It is useful to remember the famous story of the first representations of the Lumière film during which projecting the arrival of the train at the station unleashed the reactions of the spectators fleeing for fear of being knocked down. Knowing that this is a film allows to live the action as if it were real, participating emotionally but only activating the ability to act without taking real actions.

${ }^{2}$ For a discussion of these concepts see Schaeffer J.M, L'image précarie. Du dispositif photographique, Paris Editions du Seuil, 1987 